\title{
Psychoeducation for siblings of people with severe mental illness
}

Article

Accepted Version

Sin, J., Jordan, C. D., Barley, E. A., Henderson, C., Norman, I. and Whitehead, L. (2017) Psychoeducation for siblings of people with severe mental illness. Issues in Mental Health Nursing, 38 (3). pp. 283-284. ISSN 0161-2840 doi:

https://doi.org/10.1002/14651858.CD010540.pub2 Available at https://centaur.reading.ac.uk/70340/

It is advisable to refer to the publisher's version if you intend to cite from the work. See Guidance on citing.

Published version at: http://www.tandfonline.com/doi/full/10.1080/01612840.2017.1286195? scroll=top\&needAccess $=$ true

To link to this article DOI: http://dx.doi.org/10.1002/14651858.CD010540.pub2

Publisher: Taylor \& Francis

All outputs in CentAUR are protected by Intellectual Property Rights law, including copyright law. Copyright and IPR is retained by the creators or other copyright holders. Terms and conditions for use of this material are defined in the End User Agreement.

$\underline{\text { www.reading.ac.uk/centaur }}$

\section{CentAUR}


Central Archive at the University of Reading

Reading's research outputs online 


\section{() \\ Cochrane \\ Nursing Care}

The Mission of the Cochrane Nursing Care Field (CNCF) is to improve health outcomes through increasing the use of the Cochrane Library and supporting Cochrane's role by providing an evidence base for nurses and related healthcare professionals involved in delivering, leading or researching nursing care. The CNCF produces 'Cochrane Corner' columns (summaries of recent nursing-care-relevant Cochrane Reviews) that are regularly published in collaborating nursing-care-related journals. Information on the processes this Field has developed can be accessed at: http://cncf.cochrane.org/evidence-transfer-programreview-summaries

Cochrane Nursing Care Field - Cochrane Review Summary

Produced for the

\section{Mental Health Nursing Journal}

\section{TITLE: Psychoeducation for siblings of people with severe mental illness}

\section{Authors: Jacqueline Sin, Cheryl Jordan, Elizabeth Barley, Claire Henderson, lan Norman, Lisa Whitehead ${ }^{*}$}

${ }^{*}$ Corresponding author Professor Lisa Whitehead, PhD, MA, BSc (hons) RN,

School of Nursing and Midwifery, Edith Cowan University, Western Australia

A member of the Cochrane Nursing Care Field (CNCF) 


\section{- Background}

Many people with severe mental illness (SMI) have siblings. In the UK over $80 \%$ of the general population has at least one sibling (Smith 2009). The sibling relationship often outlives other relationships, including marriages and parenthood (Sin 2012). Siblings are often natural agents to promote service users' recovery but also vulnerable to mental ill health due to the negative impact of psychosis within the family (Sin 2012). Current research into siblings' experiences and needs suggest that they often do not regard themselves as carers and are rarely involved with statutory health or social services, unlike their parents who often act as the primary carers ( $\operatorname{Sin} 2012$; Smith 2009). Nonetheless, siblings' experiences of subjective and objective burden of caring may be similar to that of the primary carers (Magliano 1999). Despite research evidence supporting the effectiveness of psychoeducation for service users with SMI and their family members, in reducing relapse and promoting compliance with treatment siblings remain relatively invisible in clinical service settings as well as in research studies. Psychoeducational interventions targeting siblings and improving siblings' knowledge, coping with caring and overall wellbeing, could potentially provide a cost-effective option for supporting siblings with benefits for service users' outcomes. The provision of health care that is evidence-based and clinically effective is central to health policy and nursing practice. Ongoing efforts to improve mental health services have identified the need for mental health nurses to include psychological treatments into their practice (e.g. Department of Health 2006).

\section{- Objective/s}

The primary objective was to assess the effectiveness of psychoeducation compared with usual care or any other intervention in promoting wellbeing and reducing distress of siblings of people affected by SMI.

\section{- Intervention/Methods (information similar to Study} Characteristics)

The authors searched the Cochrane Schizophrenia Group Trials Register and screened the reference lists of relevant reports and reviews. Trial authors were contacted for unpublished and specific data on siblings' outcomes. All relevant randomised controlled trials focusing on psychoeducational interventions targeting siblings of all ages (on their own or amongst other family members including service users) of individuals with SMI, using any means and formats of delivery, i.e. individual (to the sibling-participant or to a family unit), groups, computer-based were included. Two review authors independently screened the abstracts and extracted data and two further authors independently checked the screening and extraction process. Authors of trials were contacted to ascertain siblings' participation in the trials and seek sibling-specific data in those studies where siblings' data were grouped together with other participants' (most commonly other family members'/carers') outcomes. The authors calculated the risk difference (RD), 
its $95 \%$ confidence interval $(\mathrm{Cl})$ on an intention-to-treat basis. Continuous data were presented using the mean difference statistic (MD) and 95\% Cls. Risk of bias was assessed for each included study quality of evidence was rated using Grading of Recommendations Assessment, Development and Evaluation (GRADE).

\section{- Results}

Out of 14 trials that included siblings amongst other family members in receiving psychoeducation identified, subgroup data from only one trial were available ( $n=9$ siblings out of $n=84$ family member/carer-participants), which compared a psychoeducational intervention with standard care in a community care setting. As there was insufficient evidence available, the effects of psychoeducational interventions on siblings' outcomes, such as their quality of life ( $n=9$, MD score $3.8095 \% \mathrm{Cl}-0.26$ to 7.86 , low quality of evidence), and coping with (family) burden ( $n=9, M D-8.8095 \% \mathrm{Cl}-15.22$ to -2.34, low quality of evidence), were non-significant There was no conclusive evidence that psychoeducation is of benefit for the outcomes of people with mental illness (such as mental state, hospital admission or length of hospital stay), whether their siblings received psychoeducation or not. No study data were available to address the primary outcomes: 'siblings' psychosocial wellbeing', 'siblings' distress' and adverse effects.

\section{- Conclusions}

Most studies evaluating psychoeducational interventions recruited siblings along with other family members. The proportion of siblings in these studies was low and outcomes for siblings were not reported independently from those of other types of family members. Only data from one study with nine siblings were available for the review. The limited study data provides no clear good quality evidence to indicate psychoeducation is beneficial for siblings' wellbeing or for clinical outcomes of people affected by SMI. Further randomised studies are required to understand the role of psychoeducation in addressing siblings' needs for information and support.

\section{- Implications for Practice}

Nurses are most often the healthcare providers involved in the ongoing assessment and provision of care to families, including siblings, living with a family member with a long term condition (Wilkinson et al., 2016) including those living with SMI (Fisher, 2011). Onset of SMI tends to peak around the late teenage years and early adulthood (Waraich 2004; Saha 2005), a time when many will still be living with siblings. Nurses, and in particular mental health nurses are in a prime position to both assess comprehensively the need for support and to provide psychological therapies, using a familyinclusive approach. Whilst the literature supports the effectiveness of psychoeducation for the service users affected by SMI, specific evidence on the effectiveness of psychoeducation for siblings is minimal. Nonetheless, as the wider literature repeatedly identifies that family members suffer increased vulnerability to mental and physical ill health due to the burden of caregiving, it 
is imperative for nurses to identify siblings who are often invisible to the service providers and consider siblings' need for support. Nurses can play an important role in both delivering effective evidence based practice and contributing to a body of knowledge in building this evidence.

Sin J, Jordan CD, Barley EA, Henderson C, Norman I.

Psychoeducation for siblings of people with severe mental illness.

Cochrane Database of Systematic Reviews 2015, Issue 5. Art. No.: CD010540. DOI: 10.1002/14651858.CD010540.pub2.

http://onlinelibrary.wiley.com/doi/10.1002/14651858.CD010540.pub2/pdf

\section{References}

Department of Health. End of the 'prozac nation': More counseling, more therapy, less medication to treat depression. Press Release. UK: Author, 2006.

Fisher, J. The therapeutic role of the mental health nurse: implications for the practice of psychological therapies. PhD Thesis, Southern Cross University, 2011.

Magliano L, Fadden G, Fiorillo A, Malangone C, Sorrentino D, Robinson A, et al. Family burden and coping strategies in schizophrenia: are key relatives really different to other relatives. Acta Psychiatrica Scandinavica 1999; 99: 10-5.

Saha S, Chant D, Welham J, McGrath J. A systematic review of the prevalence of schizophrenia. PLoS Medicine 2005; 2(5): e141. [PUBMED: PMC1140952]

Sin J, Moone N, Harris P, Scully E, Wellman N. Understanding the experiences and service needs of siblings of individuals with first episode psychosis: A phenomenological study. Early Intervention in Psychiatry 2012; 6: 53-9.

Smith J, Fadden G, O'Shea M. Interventions with siblings. In: Lobban F, Barrowclough $\mathrm{C}$ editor(s). A Casebook of Family Interventions for Psychosis. Chichester: Wiley and Sons, 2009: 185-200

Waraich P, Goldner EM, Somers JM, Hsu L. Prevalence and incidence studies of mood disorders: a systematic review of the literature. Canadian Journal of Psychiatry 2004; 49(2): 124-38.

Wilkinson M, Whitehead L, Crowe $M$. Nurses perspectives on long-term condition self-management: a qualitative study. Journal of Clinical Nursing 2016; 25(1-2): 240-6. 